\title{
COGNIC̄õES PERFECIONISTAS NO DESEMPENHO DE UMA TAREFA DE REVISÃO DE TEXTO NUMA AMOSTRA DE JOVENS-ADULTOS UNIVERSITÁRIOS
}

\author{
PERFECT COGNITIONS IN THE PERFORMANCE OF A TEXT REVIEW TASK IN \\ A SAMPLE OF YOUNG ADULTS FROM THE UNIVERSITY
}

\author{
Coelho, J.1 ${ }^{1}$ Faísca, L. ${ }^{2}$, Ros, A. ${ }^{3}, \&$ Carmo, C. ${ }^{4}$ \\ PSIQUE • E-ISSN 2183-4806 • VOLUME XVII • ISSUE FASCÍCULO 1 \\ $1^{\text {ST }}$ JANUARY JANEIRO - 30 TH JUNE JUNHO 2021 PP. 74-95 \\ DOI: ttps://doi.org/10.26619/2183-4806.XVII.NT.3 \\ Submited on 09.03.21 Submetido a 09.03.21 \\ Accept on 14.05.21 Aceite a 14.05.21
}

\begin{abstract}
Resumo
O conceito de perfecionismo tem originado cada vez mais interesse por parte de muitos investigadores e clínicos, sendo consensual a necessidade de compreender melhor o papel das cognições perfecionistas no desempenho de determinada tarefa. Assim, o principal objetivo deste estudo, com design quasi-experimental, foi compreender de que forma as cognições perfecionistas influenciam o desempenho de jovens universitários, com diferentes niveis de perfecionismo, numa tarefa de revisão de texto. Num primeiro momento, foram avaliados os níveis de perfecionismo de 258 estudantes com a versão reduzida da Escala Quase Perfeita (SAPS). Num segundo momento, foram selecionados os participantes com níveis mais elevados $(n=12)$ e mais baixos de perfecionismo $(n=20)$. Os estudantes preencheram a Escala Quase Perfeita (APS), o Inventário de Cognições Perfecionistas (PCI), a Escala Multidimensional de Perfecionismo (HMPS) e realizaram uma tarefa de revisão de texto. Os resultados mostraram que, no geral, os perfecionistas demoraram mais tempo na conclusão da tarefa e que participantes com níveis mais elevados de perfecionismo apresentavam uma eficácia reduzida na deteção de erros na tarefa, demonstrando a importância de considerar o tempo investido, os erros e o viés de resposta ao investigar a relação perfecionismo-desempenho. Concluiu-se que
\end{abstract}

\footnotetext{
1 Universidade do Algarve (Mestre em Psicologia Clínica e da Saúde), Faculdade de Ciências Humanas e Sociais, Departamento de Psicologia e Ciências da Educação, Campus de Gambelas, 8005-139 Faro, Portugal, email: a50563@ualg.pt 2 Centro de Investigação em Biomedicina, Universidade do Algarve, Faculdade de Ciências Humanas e Sociais, Departamento de Psicologia e Ciências da Educação, Campus de Gambelas, 8005-139 Faro, Portugal, email: lfaisca@ualg.pt

3 Centro de Investigação em Psicologia (CIP-UAL), Universidade do Algarve, Faculdade de Ciências Humanas e Sociais, Departamento de Psicologia e Ciências da Educação, Campus de Gambelas, 8005-139 Faro, Portugal, email: aros@ualg.pt

4 Centro de Investigação em Psicologia (CIP-UAL), Universidade do Algarve, Faculdade de Ciências Humanas e Sociais, Departamento de Psicologia e Ciências da Educação, Campus de Gambelas, 8005-139 Faro, Portugal, email: cgcarmo@ualg.pt
}

Autor para Correspondência: Joana Coelho - Universidade do Algarve (Mestre em Psicologia Clínica e da Saúde), Faculdade de Ciências Humanas e Sociais, Departamento de Psicologia e Ciências da Educação, Campus de Gambelas, 8005-139 Faro, Portugal, email: a50563@ualg.pt 
os níveis de perfecionismo demonstram ser inversamente proporcionais à eficiência, corroborando estudos anteriores.

Palavras-Chave: Perfecionismo; Cognições perfecionistas; Desempenho; Estudantes universitários.

\begin{abstract}
The concept of perfectionism has generated growing interest on the part of many researchers and clinicians, and there is a consensus on the need to better understand the role of perfectionist cognitions in the performance of a given task. Thus, the main objective of this study with quasiexperimental design was to understand how perfectionist cognitions influence the performance of young university students, with different levels of perfectionism, in a text review task. Initially, the perfectionism levels of 258 students with the reduced version of the Near Perfect Scale (SAPS) were evaluated. In a second stage, participants with higher levels $(n=12)$ and lower levels of perfectionism ( $n=20$ ) were selected. The students completed the Almost Perfect Scale (APS), the Perfectionist Cognition Inventory (PCI), the Multidimensional Perfectionism Scale (HMPS) and performed a text review task. The results showed that, in general, perfectionists take longer to complete the task and that participants with higher levels of perfectionism had a reduced effectiveness in detecting errors in the task, demonstrating the importance of considering the time invested, errors and the response bias when investigating the perfectionism-performance relationship. It was concluded that the levels of perfectionism were inversely proportional to efficiency, corroborating previous studies.
\end{abstract}

Keywords: Perfecionism, Perfectionist Cognitions, Performance, University students.

\title{
Introdução
}

O perfecionismo é definido como um traço de personalidade multidimensional (Gaudreau \& Thompson, 2010; Stoeber $\delta$ Otto, 2006) que representa tanto a tendência de lutar pela perfeição como a de avaliar o Eu de uma forma crítica (Gaudreau \& Thompson, 2010). Descrito como uma caraterística complexa e que apresenta várias dimensões, aparecendo sob diferentes formas e aspetos - alguns podem ser funcionais e adaptativos, enquanto outros disfuncionais e desadaptativos (Enns \& Cox, 2002; Stoeber \& Otto, 2006).

Os sujeitos perfecionistas caraterizam-se pela preocupação constante em atingir metas excessivamente elevadas e irrealistas, tendendo a realizar avaliações autocríticas. As experiências de insucesso são normalmente sobregeneralizadas, prestando uma atenção especial aos fracassos em detrimento dos sucessos (Ram, 2005).

Atualmente a investigação na área do perfecionismo é extensa, particularmente acerca da sua importância no desenvolvimento e na manutenção de sintomas psicopatológicos (e.g., Egan et al., 2012). Contudo, o estudo sobre o papel do perfecionismo no desempenho de tarefas é ainda reduzido e inconclusivo. Surge assim a pertinência da presente investigação. 


\section{Perfecionismo: Definição e natureza}

O conceito de perfecionismo tornou-se objeto de interesse e de atenção por parte de clínicos e investigadores no âmbito da psicologia a partir da última metade do século XX (e.g., Hamachek, 1978; Hollender, 1965). O aumento da investigação neste domínio permitiu um conhecimento mais aprofundado do conceito e da influência deste traço em vários quadros clínicos, nomeadamente perturbações depressivas (e.g., Hewitt $\delta$ Flett, 1991; Sherry et al., 2003), perturbações da alimentação e da ingestão (e.g., Egan et al., 2011; Shafran et al., 2002) e perturbação obsessiva-compulsiva (e.g., Antony et al., 1998; Wu \& Cortesi, 2009).

Perfecionismo é geralmente considerado como uma disposição de personalidade que envolve a procura pela perfeição, o estabelecimento de padrões de desempenho excessivamente elevados e a avaliação crítica de si mesmo relativamente a falhas percebidas (Stoeber, 2018). Contudo, ao longo do tempo a definição e a natureza do construto foi alvo de controvérsias, dando origem a diferentes perspetivas e abordagens teóricas (Shafran \& Mansell, 2001).

As primeiras definições de perfecionismo salientavam unicamente os aspetos clínicos deste conceito. Horney (1945) considerou o perfecionismo como uma disposição de personalidade altamente neurótica, sem quaisquer aspetos positivos. Ainda numa leitura psicodinâmica, Adler (1956) argumentou que a procura pela perfeição era considerada um aspeto natural e inato do desenvolvimento humano, no sentido de maximizar o talento ou o potencial dos sujeitos. Segundo o autor, os perfecionistas adaptativos procuravam alcançar objetivos reais, enquanto os perfecionistas desadaptativos poderiam tornar-se obsessivos relativamente aos objetivos delineados e tendiam a ter medo da crítica.

De acordo com Hollender (1965, 1978), o perfecionismo definia-se como a prática de exigir a si próprio ou ao outro um melhor desempenho do que o realmente requerido pela situação. Na mesma perspetiva, Burns (1980) descreveu o perfecionismo como uma "rede de cognições" que incluem expetativas, interpretações e avaliações sobre o próprio e os outros. Segundo este autor, os sujeitos perfecionistas estabelecem padrões e/ou objetivos irrealistas por serem demasiado elevados e rígidos, definindo o seu valor pessoal de forma contingente à concretização desses padrões e objetivos.

Apesar das várias definições no âmbito de uma conceção unidimensional do perfecionismo, que sublinham a natureza patológica e clínica deste traço de personalidade, parece existir consenso quanto à principal característica dos sujeitos perfecionistas: os padrões pessoais de desempenho excessivamente elevados.

Hamacheck (1978) sugeria que o perfecionismo compreendia aspetos adaptativos e aspetos desadaptativos. De acordo com a autora, a principal distinção entre perfecionismo normal e neurótico remetia para a capacidade de os perfecionistas normais conseguirem permitir pequenas falhas no seu desempenho, aceitando-o como bem-sucedido. Por outro lado, os perfecionistas neuróticos eram caraterizados por serem excessivamente preocupados com os erros, apresentando uma preocupação constante relativamente ao medo de falhar. Segundo a autora, a preocupação excessiva relativamente aos erros levaria os sujeitos perfecionistas a lutarem por alcançar os objetivos delineados por medo do fracasso e não por uma necessidade de realização (Hamachek, 1978).

No início da década de 90, a abordagem multidimensional, que demonstrava os aspetos desadaptativos e os aspetos adaptativos do perfecionismo, ganhou uma maior relevância com o contributo de Frost et al. (1990) e Hewitt e Flett (1991). A conceção unidimensional, que se focava 
apenas nos aspetos intrapessoais, deixou de ser exclusiva e as abordagens multidimensionais centradas também na componente interpessoal passaram a assumir um papel de relevo.

Neste contexto foram desenvolvidos instrumentos de avaliação dos vários componentes do perfecionismo, como foi o caso da Escala Multidimensional de Perfecionismo (MPS; Frost et al., 1990; Hewitt \& Flett, 1991).

Frost et al. (1990) desenvolveram uma escala denominada de Escala Multidimensional de Perfecionismo (Frost Multidimensional Perfectionism Scale, FMPS), onde diferenciaram as dimensões do construto: Padrões Pessoais (PP), Preocupação com os Erros (PE), Dúvidas sobre as Ações (DA), Expetativas Parentais (EP), Críticas Parentais (CP) e Organização (O). Destes, quatro dizem respeito a aspetos do perfecionismo direcionados para o próprio (PP, PE, DA e O) e os restantes refletem a perceção de exigências impostas por terceiros (EP e CP).

Com a mesma designação, Hewitt e Flett (1991) desenvolveram a Escala Multidimensional de Perfecionismo (Multidimensional Perfectionism Scale of Hewitt and Flett, HMPS), onde distinguiram três dimensões: Perfecionismo Auto-Orientado (PAO), Perfecionismo Socialmente Prescrito (PSP) e Perfecionismo Orientado para os Outros (POO). A principal diferença entre as três dimensões diz respeito ao objeto a quem o comportamento perfecionista é dirigido (e.g., Perfecionismo Auto-Orientado vs. Perfecionismo Orientado para os Outros) ou a quem é exigido o comportamento perfecionista (e.g., Perfecionismo Socialmente Prescrito).

Sucintamente, o PAO refere-se à tendência do sujeito em estabelecer para si padrões de desempenho elevados, excessivos e irrealistas (dimensão intra-individual). O PSP remete para a crença das expetativas irrealistas dos outros para com o sujeito (dimensão interpessoal) (O'Connor et al., 2009). E, por último, o POO (dimensão interpessoal) relaciona-se com às expetativas elevadas e irrealistas que o sujeito apresenta relativamente aos outros (Flett et al., 2002).

Ainda segundo uma conceção multidimensional foi desenvolvida uma outra medida, a Escala Quase Perfeita (Almost Perfect Scale-Revised, APS-R; Slaney et al., 2001) que é frequentemente usada para categorizar os sujeitos em perfecionistas adaptativos e desadaptativos. O APS-R contém três subescalas: Padrões Elevados (P), Ordem (O) e Perceção da Discrepância (D). A subescala $P$ mede os altos padrões pessoais de desempenho e de realização; a subescala $D$ mede a perceção dos sujeitos de si mesmos como falha ao atender os seus padrões pessoais de desempenho; e, por último, a subescala $\mathrm{O}$ mede a preferência por limpeza e organização. Ambos tendem a apresentar valores altos na subescala $\mathrm{P}$ e na $\mathrm{O}$ e apenas os perfecionistas desadaptativos apresentam valores altos na subescala D (Slaney et al., 2001).

Deste modo, é possível compreender que embora o perfecionismo apresente aspetos positivos (adaptativos) e aspetos negativos (desadaptativos), são estes últimos que fortalecem a relação entre o construto e os problemas psicológicos - evidenciada há várias décadas em descrições de casos clínicos (e.g., perturbação depressiva, perturbação de ansiedade, perturbação da alimentação e da ingestão) (Macedo et al., 2007).

A evidência empírica de que o perfecionismo é um traço de personalidade presente em vários quadros clínicos permite considerá-lo, segundo Shafran et al. (2002), como um conceito transdiagnóstico caracterizado por uma dependência excessiva de autoavaliações exigentes relativamente a determinados padrões pessoais, em pelo menos um domínio.

Numa análise clínica, o perfecionismo pode ser avaliado do ponto de vista comportamental (e.g., verificação, comportamentos repetitivos) ou do ponto de vista cognitivo (e.g., pensamentos repetitivos negativos, ruminação, preocupação). 
Flett et al. (2015), na tentativa de melhor compreender os aspetos cognitivos deste traço de personalidade, desenvolvem a Teoria da Cognição do Perfecionismo. Trata-se de um modelo teórico que propõe uma estrutura concetual para explorar e explicar os mecanismos, os processos e os resultados cognitivos que enfatizam o perfecionismo.

A Teoria da Cognição do Perfecionismo postula que: o perfecionismo é associado a um início rápido, frequente e prolongado de ruminação; o sujeito perfecionista encontra-se propenso a experienciar uma variedade de tipos de pensamento e de perseverança cognitiva; a excessiva ativação cognitiva desencadeia o desenvolvimento de memórias de erros, falhas e experiências stressantes. Esta atividade cognitiva é acompanhada por uma hipervigilância e por uma tendência cognitiva de acreditar na possibilidade de existirem erros, falhas ou avaliações sociais negativas (Flett et al., 2015).

Assim, com base na revisão de literatura efetuada no âmbito da presente investigação, pode-se sublinhar a natureza multidimensional (adaptativa e desadaptativa) e transdiagnóstica do perfecionismo que remete para a existência de duas componentes de avaliação e de análise do construto em estudo: a componente comportamental e a componente cognitiva.

Considerando esta última, surgiu a pertinência de compreender de que forma o perfecionismo pode influenciar o desempenho, i.e., averiguar se os níveis de perfecionismo podem estar positivamente ou negativamente relacionados com a eficiência do desempenho numa determinada tarefa.

\section{Perfecionismo no desempenho}

Considerando a conceptualização do perfecionismo e a importância que os perfecionistas colocam nos elevados padrões de desempenho, a presença de níveis elevados de perfecionismo e o desempenho dos sujeitos tem sido estudada em diversos contextos, nomeadamente, no contexto do desempenho académico (e.g., Bong et al., 2014), da performance desportiva (e.g., Dunn et al., 2006) e na realização de pequenas tarefas de leitura e/ou deteção de erros (e.g., Ishida, 2005).

Ishida (2005), num estudo sobre o desempenho absoluto e a eficiência de sujeitos perfecionistas e não perfecionistas, procurou compreender a relação entre o perfecionismo e o desempenho na resolução de problemas. Os participantes realizaram uma tarefa de resolução de problemas, sendo instruídos a procurar as informações pertinentes para resolver a tarefa.

Foram entregues arquivos a todos os participantes, contendo informações relevantes (i.e., as informações necessárias para resolver o problema presente na tarefa) e informações irrelevantes. Com base numa avaliação prévia das cognições perfecionistas dos participantes, foram constituídos dois grupos: Perfecionistas e Não Perfecionistas. Os perfecionistas apresentaram pontuações mais baixas na tarefa de resolução de problemas e investiram mais tempo nas informações irrelevantes, permitindo concluir que o perfecionismo se encontra associado a uma eficiência reduzida.

A descoberta de uma relação inversa entre o perfecionismo e a eficiência levou Stoeber e Eysenck (2008) a replicarem o estudo de Ishida (2005), explorando as relações entre o perfecionismo, o desempenho e a eficiência ao analisar como as duas dimensões do perfecionismo (P e D) previam o desempenho, o esforço e a eficiência numa tarefa de prova de leitura que exigia aos participantes detetar os Erros de Ortografia, de Gramática e de Formato de Texto. O tempo de 
realização da tarefa foi definido previamente pelos autores, tendo os participantes de assinalar quando a concluíssem.

Os resultados mostraram que existia uma relação positiva entre os $\mathrm{P}$ e os Falsos Alarmes (erros detetados incorretamente), sugerindo que quanto mais elevados fossem os padrões maior a tendência para encontrar falhas - o que significava uma menor eficiência. Por outro lado, era evidente uma relação negativa entre D e os Acertos (erros detetados corretamente), mostrando que os sujeitos que se percecionavam como incapazes de cumprir os seus padrões tendiam a ser mais cautelosos e conservadores, i.e., a não quererem encontrar falhas mesmo quando estas existiam (Stoeber \& Eysenck, 2008).

Posteriormente, Stoeber (2011) replicou o seu estudo anterior com o objetivo de expandir as descobertas alcançadas sobre o perfecionismo, a Eficiência e o Viés de Resposta no desempenho de uma prova de leitura utilizando uma amostra maior, diferentes medidas de perfecionismo e um texto diferente. Os resultados refletiram a importância de considerar o perfecionismo como uma caraterística de personalidade multidimensional e diferenciar duas dimensões principais: Esforços Perfecionistas e Preocupações Perfecionistas.

De acordo com os dados obtidos, sujeitos com altos níveis de Esforços Perfecionistas mostraram menor Eficiência no desempenho da prova, corroborando os anteriores resultados deste autor em 2008. Além disso, demonstraram uma relação positiva com os Falsos Alarmes e uma relação negativa com o Viés de Resposta, indicando que esses sujeitos tendiam a relatar erros mesmo quando estes não existiam. Neste sentido, investiam mais esforço e demonstravam uma relação positiva com o tempo investido para completar a tarefa de revisão de texto.

Também foi possível verificar que as Preocupações Perfecionistas apresentaram uma relação parcial negativa com o número de Acertos e uma relação parcial positiva com o Viés de Resposta, quando a influência dos Esforços Perfecionistas não foi considerada. Contudo, como a tarefa utilizada não foi a mesma do estudo anterior, não é claro se os resultados são específicos para o desempenho da prova de leitura.

Neste sentido, o autor ressalta a importância de considerar não apenas o desempenho absoluto e as respostas corretas (Acertos), mas também o desempenho relativo (ou Eficiência) e as respostas incorretas ao investigar a relação perfecionismo-desempenho (Stoeber, 2011). Assim, pode-se ter em consideração o esforço investido para atingir o nível de desempenho (Eysenck $\mathcal{E}$ Calvo, 1992).

Apesar da existência de algumas de investigações (e.g., Bong et al., 2014; Dunn et al., 2006) que apresentam interesse em analisar a componente cognitiva do perfecionismo, usam maioritariamente medidas de autorrelato e não medidas de tarefas de execução. Deste modo, torna-se pertinente desenvolver mais estudos utilizando esta metodologia e por esse motivo, com base no estudo pioneiro de Stober e Eysenck (2008), desenvolvemos a presente investigação com o objetivo de analisar de que forma as cognições perfecionistas podem influenciar o desempenho numa tarefa de revisão de texto.

De modo a alcançar o objetivo geral, delinearam-se os seguintes objetivos específicos: (1) Explorar se existem diferenças nas várias dimensões de perfecionismo em sujeitos com altos e baixos níveis de perfecionismo; (2) Avaliar as relações entre as várias dimensões do perfecionismo; (3) Verificar se existem diferenças no desempenho da Tarefa de Revisão de Texto em sujeitos com altos e baixos níveis de perfecionismo; (4) Analisar as relações entre os níveis de perfecionismo e a eficiência na resolução da revisão de texto; (5) Explorar as relações entre as 
cognições perfecionistas e a eficiência na realização da tarefa; (6) Compreender de que forma o perfecionismo influencia a eficiência na resolução da tarefa, nas diferentes modalidades de erro.

Espera-se, de acordo com os objetivos delineados anteriormente, encontrar: diferenças entre os sujeitos com altos níveis de perfecionismo e os sujeitos com baixos níveis de perfecionismo nas diversas dimensões de perfecionismo em estudo (1); níveis elevados de perfecionismo associados a maior frequência das cognições perfecionistas e a maior perfecionismo no global (2); sujeitos com altos niveis de perfecionismo obtenham menor desempenho na resolução da tarefa relativamente aos sujeitos com baixos níveis de perfecionismo (3); sujeitos com altos níveis de perfecionismo demonstrem ser menos eficientes na resolução da tarefa (4); sujeitos com cognições perfecionistas frequentes sejam menos eficientes na resolução da tarefa face a sujeitos que apresentem baixas cognições perfecionistas (5); sujeitos com niveis elevados de perfecionismo apresentem menor eficiência na resolução da tarefa nas diversas modalidades de erro.

\section{Método}

\section{Participantes}

A amostra total $(n=258)$ foi composta por sujeitos com nacionalidade portuguesa de ambos os géneros, sendo 178 do género feminino (69\%) e 80 do género masculino (31\%), com idades compreendidas entre os 17 e os 40 anos $(M=21.02$; $D P=2.98)$. Descrevendo os participantes de um modo geral, a sua maioria eram solteiros (97.70\%), estudantes universitários que frequentavam a licenciatura (99.20\%), maioritariamente o curso de Psicologia (20.20\%) e com rendimento escolar médio suficiente (10 a 13 valores) (50\%). Grande parte dos participantes (97.70\%) não realizavam tratamento psicológico e/ou psiquiátrico nem se encontravam como trabalhadores-estudantes (86\%).

Ao analisar os níveis extremos do perfecionismo da amostra total, esta foi dividida em dois grupos distintos: os participantes que apresentavam altos níveis de perfecionismo $(n=50)$ e baixos níveis de perfecionismo $(n=70)$. Considerando as variáveis sociodemográficas em estudo, comparou-se os dois grupos com recurso ao Teste $t$ de Student para amostras independentes (variáveis escalares) e ao Teste do Qui-quadrado (variáveis nominais) e percecionou-se que não existiram diferenças estatisticamente significativas.

A amostra final foi composta por 32 sujeitos (12 sujeitos Perfecionistas e 20 sujeitos Não Perfecionistas), que aceitaram dar continuidade ao estudo. Caraterizando a amostra, 25 participantes eram do género feminino (78.10\%) e 7 do género masculino (21.90\%), com idades compreendidas entre os 18 e os 31 anos $(M=21.34$; $D P=3.01)$. A maioria dos sujeitos eram solteiros $(93.80 \%)$, frequentavam a licenciatura (96.90\%) do curso de Psicologia (56.30\%) com um escolar médio bom (14 a 16 valores) (53.10\%). Nenhum dos participantes se encontrava a realizar tratamento psicológico e/ou psiquiátrico e uma baixa percentagem afirmou ser trabalhador-estudante $(12.50 \%)$.

A comparação entre a amostra total $(n=258)$ e a amostra final $(n=32)$, relativamente às variáveis sociodemográficas, permitiu verificar que não existiram diferenças significativas entre si. Deste modo, podemos concluir que a amostra final é representativa da amostra total. 


\section{Tipo de estudo}

Para a realização do estudo foi utilizado um paradigma de investigação quantitativa, do tipo quasi-experimental (Sousa et al., 2007).

O desenho da presente investigação é considerado transversal. Apesar de terem existido dois momentos de recolha de dados, no primeiro momento pretendeu-se apenas selecionar sujeitos com valores extremos de perfecionismo (altos/baixos). Posteriormente a essa seleção, os participantes foram avaliados num único momento.

\section{Medidas}

De forma a recolher informações sociodemográficas pertinentes relativamente à amostra, foi aplicado um breve questionário desenvolvido no âmbito deste estudo que permitiu caracterizar os participantes quanto ao género, à idade, à nacionalidade, ao estado civil, ao nível de ensino, ao curso, ao rendimento escolar, à profissão e à existência ou não de tratamento psicológico e/ou psiquiátrico.

A Escala Quase Perfeita (APS) avalia o perfecionismo em três subescalas: Padrões elevados (P), Ordem (O) e perceção da Discrepância (D) (Slaney et al., 1995, 2001). As duas primeiras subescalas representam os aspetos positivos do perfecionismo, enquanto a última remete para os aspetos negativos desse traço de personalidade (Slaney et al., 2000, 2001) - contribuindo para discriminar os sujeitos perfecionistas adaptativos e desadaptativos. O instrumento é composto por 23 itens que se distribuem numa escala de 7 pontos, na qual 1 se refere a Discordo Fortemente e o 7 refere-se a Concordo Fortemente. Os coeficientes de estrutura das três dimensões da escala oscilam entre .42 e .88. Os coeficientes de alfa de Cronbach foram .85 para a subescala Padrões, .82 para a subescala Ordem e .91 para a subescala Discrepância, indicando que a versão original da escala apresenta valores adequados de consistência interna (Slaney et al., 2001).

A Escala Quase Perfeita, versão reduzida (SAPS), composta por 8 itens, avalia o traço de perfecionismo em apenas duas subescalas: Padrão (P) e Discrepância (D). Rice, Richardson e Tueller (2014), com base no trabalho de Stoeber e Otto (2006), retiraram a subescala Ordem por esta não ter emergido como uma dimensão central do perfecionismo. No âmbito deste estudo, foi traduzida para português e encontra-se em adaptação para a população portuguesa. Ao realizar a análise de fidelidade da SAPS, foi possível verificar que os valores obtidos para a subescala Padrão e para a subescala Discrepância foram ambos de $\alpha=.70$. O valor obtido para o total da escala foi de .63, permitindo concluir que a aplicabilidade do instrumento apresenta uma consistência interna aceitável. Kline (1999) refere que, quando se estuda construtos psicológicos, os valores abaixo de .70 podem ser esperados devido à diversidade de construtos que estão a ser medidos.

O Inventário de Cognições Perfecionistas (PCI) é formado por uma lista de pensamentos perfecionistas que tem como intuito avaliar a frequência das cognições associadas ao perfecionismo. Constituído por 25 itens, contém três dimensões: preocupação com os erros, padrões pessoais e procura da perfeição. As respostas são dadas numa escala de 5 pontos, na qual 1 corresponde a Nunca e 5 corresponde a Sempre. O instrumento foi traduzido e adaptado à população portuguesa por Carmo et al. (2018), apresentando propriedades psicométricas adequadas. Neste estudo, o valor de alfa de Cronbach encontrado foi de .90 para o total da escala. Neste sentido, 
apresentando um valor de consistência interna elevado, a aplicabilidade do Inventário das Cognições Perfecionistas (PCI) demonstra ser confiável.

A Escala Multidimensional de Perfecionismo (Hewitt \& Flett, 1991) é composta por 45 itens de resposta fechada, distribuídos por três subescalas que medem as três dimensões do perfecionismo: Perfecionismo Auto-Orientado (PAO), Perfecionismo Socialmente Prescrito (PSP) e Perfecionismo Orientado para os Outros (POO). As respostas dos sujeitos são assinaladas numa escala de 7 níveis de concordância, correspondendo 1 a Discordo Completamente e 7 a Concordo Completamente, embora 19 itens sejam cotados em sentido inverso.

Apresentando uma boa consistência interna, foi traduzida e adaptada para a população portuguesa por Soares et al. (2003), exibindo adequadas qualidades psicométricas. No presente estudo, as subescalas PAO, PSP e POO obtiveram valores elevados de consistência interna, $\alpha=$ $.90 ; \alpha=.90 ; \alpha=.80$, respetivamente. O alfa de Cronbach de .90 identificado para o total da escala demonstra um bom indicador de fidelidade relativamente ao presente instrumento, apresentando uma consistência interna aceitável.

A tarefa de revisão de texto foi baseada na tarefa do estudo original de Stoeber e Eysenck (2008), nomeadamente a inserção de três tipos de erros (Erros de Ortografia, de Gramática e de Formato de Texto) no texto e o tempo de realização da prova (35 minutos), tendo como objetivo medir o desempenho dos participantes.

O texto foi adaptado de um excerto de um artigo científico publicado em língua portuguesa. Foram introduzidas alterações de forma a inserir 39 erros: 12 de Ortografia (e.g., Questões relativas aos ábitos alimentares, de higiene e sono), 15 de Gramática (e.g., É necessário estabelecendo prioridades na educação e saúde) e 12 de Formato de Texto (e.g., Camacho et al., 2016).

No final de cada linha do texto encontravam-se três caixas. Cada uma correspondia a um tipo de erro, onde o sujeito deveria assinalar os que encontrasse. No caso de ausência de erro numa linha do texto, o sujeito não deveria assinalar nada. Por outro lado, poderia existir mais do que um tipo de erro numa só linha e, nesse caso, deveria assinalar os erros nas caixas correspondentes ao tipo de erro encontrado.

No início da realização da tarefa de revisão, as regras foram apresentadas oralmente e em formato papel, num cartão que podia ser consultado no decorrer da prova. A tarefa deveria ser realizada num período máximo de 35 minutos, sendo cronometrado o tempo de realização de cada participante.

\section{Procedimentos}

Anteriormente ao presente estudo, foi feito um estudo piloto com 21 estudantes universitários portugueses. Os instrumentos de medida utilizados foram o Questionário de Caraterização Sociodemográfica, a Escala Quase Perfeita (APS) e o Inventário das Cognições Perfecionistas (PCI). Como os participantes não reportaram dúvidas no preenchimento do protocolo piloto, optou-se por incluir os dados do estudo piloto no estudo final. Neste último foram feitos alguns ajustes, nomeadamente adicionada a Escala Multidimensional de Perfecionismo (HMPS).

Relativamente à investigação que apresentamos, esta foi dividida em dois momentos. No primeiro momento foi realizada a recolha de dados, onde foram aplicados o Questionário de Caraterização Sociodemográfica e a Escala Quase Perfeita, versão reduzida (The Short Form of the Revised Almost Perfect Scale, SAPS; Rice et al., 2014), de modo a selecionar os participantes 
com altos e baixos níveis de perfecionismo. Foi também facultado um consentimento informado, comprovando a participação voluntária e a confidencialidade de todos os dados recolhidos.

Recorrendo ao programa de tratamento de dados estatísticos Statistical Package for the Social Sciences (IBM SPSS Statistics - Versão 25.0), foi realizado um ponto de corte para o limite superior e outro para o limite inferior. Através da função visual binning do software, foram definidos os pontos de corte a partir da variável Total da Escala Quase Perfeita, versão reduzida (SAPS) com o intuito de identificar os participantes com níveis altos e baixos de perfecionismo.

Deste modo, foram selecionados e contactados os participantes que apresentavam níveis extremos de perfecionismo. Aos sujeitos que aceitaram colaborar na segunda fase da investigação, foram aplicados a Escala Quase Perfeita (Almost Perfect Scale, APS; Slaney et al., 1995); Inventário de Cognições Perfecionistas (Perfectionism Cognitions Inventory, PCI; Flett et al., 1998), adaptado por Carmo et al. (2018); Escala Multidimensional de Perfecionismo (Multidimensional Scale of Perfectionism, HMPS; Hewitt \& Flett, 1991), adaptada por Soares et al. (2003); e a Tarefa de Revisão de Texto, adaptada do estudo de Stoeber e Eysenck (2008).

Para uma melhor compreensão do procedimento realizado nos dois momentos do presente estudo, foi desenvolvido com o apoio da Figura 1, um resumo de ambos os momentos com os valores das respetivas amostras e instrumentos de medida utilizados.

\section{FIGURA 1}

Procedimento de recolha de dados (dois momentos)

\begin{tabular}{cc}
\hline $\mathbf{1}^{\mathbf{0}}$ Momento & $\mathbf{2}^{\mathbf{0}}$ Momento \\
\hline Amostra inicial $(N=258)$ & Sub amostra selecionada $(N=32)$ \\
\hline Perfecionistas $(n=50)$ & Perfecionistas $(n=12)$ \\
Neutro $(n=138)$ & - \\
Não Perfecionistas $(n=70)$ & Não Perfecionistas $(n=20)$ \\
\hline Avaliação Sociodemográfica (QSD) & Escala Quase Perfeita (APS) \\
Escala Quase Perfeita, v. reduzida (SAPS) & Inventário das Cogniç̃es Perfecionistas (PCI) \\
& Escala Multidimensional de Perfecionismo (HMPS)
\end{tabular}

Posteriormente à recolha dos dados, estes foram organizados e transformados para uma base de dados em suporte informático. Todas as análises de dados foram realizadas recorrendo ao programa de tratamento de dados estatísticos mencionado anteriormente (IBM SPSS Statistics Versão 25.0), para o sistema operativo Windows.

\section{Resultados}

\section{Análise dos níveis de perfecionismo}

A versão reduzida da Escala Quase Perfeita (SAPS) foi aplicada com o intuito de compreender a existência de diferenças relativas ao nível de perfecionismo entre o grupo Não Perfecionistas e o grupo Perfecionismo. Iremos analisar se as diferenças foram significativas na tabela seguinte. 


\section{TABELA 1}

Média, Desvio-Padrão e Diferenças entre o grupo Não Perfecionistas $(N=70)$ e o grupo Perfecionistas $(N=$ 50) na Escala Quase Perfeita, versão reduzida (SAPS)

\begin{tabular}{|c|c|c|c|c|c|c|c|}
\hline \multirow{2}{*}{$\begin{array}{l}\text { SAPS } \\
\text { Subescalas }\end{array}$} & \multicolumn{2}{|c|}{$\begin{array}{l}\text { Não Perfecionistas } \\
(N=70)\end{array}$} & \multicolumn{2}{|c|}{ Perfecionistas $(N=50)$} & \multirow[b]{2}{*}{ d de Cohen } & \multirow[b]{2}{*}{$\boldsymbol{t}$} & \multirow[b]{2}{*}{$\boldsymbol{p}$} \\
\hline & M & $D P$ & M & $D P$ & & & \\
\hline Padrão & 18.07 & 3.31 & 23.88 & 1.92 & -2.24 & -12.11 & $.00^{* \star *}$ \\
\hline Discrepância & 11.16 & 3.57 & 21.50 & 2.38 & -3.52 & -19.01 & $.00 * \star *$ \\
\hline Total & 29.23 & 2.63 & 45.38 & 2.51 & -6.27 & -33.84 & $.00 * \star \star$ \\
\hline
\end{tabular}

Nota. $M=$ Média; $D P=$ Desvio-Padrão; $t=$ Teste $t$ de Student para amostras independentes; $d$ de Cohen; Escala Quase Perfeita, versão reduzida (SAPS) de Rice et al. (2014)

${ }^{\star} p<.05 .{ }^{* *} p<.01 .{ }^{* * *} p<.00$

Os resultados obtidos foram ao encontro do esperado, permitindo verificar diferenças estatisticamente significativas entre os dois grupos nas diferentes subescalas e no valor Total da Escala Quase Perfeita, versão reduzida (SAPS). O grupo Perfecionistas apresentou sempre valores médios superiores.

Ao calcular a magnitude do efeito, esta mostrou ser significativamente diferente entre a subescala Padrão $(d=-2.24)$, a subescala Discrepância $(d=-3.52)$ e a variável Total $(d=-6.27)$. Com base nestes valores pode-se verificar a existência de um efeito "grande" $(|d|>0.80)$.

Considerando os objetivos do presente estudo, as análises foram realizadas com a amostra final $(N=32)$ - o grupo Não Perfecionistas é composto por 20 sujeitos e o grupo Perfecionistas pelos restantes 12 sujeitos.

\section{Análise intergrupal das várias componentes do perfecionismo}

Recorrendo ao Teste de Mann-Whitney para amostras independentes, pretendeu-se comparar os valores médios da Escala Quase Perfeita (APS), versão completa, do Inventário das Cognições Perfecionistas (PCI) (Tabela 2) e da Escala Multidimensional de Perfecionismo (HMPS) (Tabela 3) em cada um dos grupos.

\section{TABELA 2}

Média, desvio-padrão e diferenças entre o grupo Não Perfecionistas ( $N=20)$ e o grupo Perfecionistas ( $N=$ 12) na Escala Quase Perfeita (APS) e no Inventário das Cognições Perfecionistas (PCI)

\begin{tabular}{|c|c|c|c|c|c|c|c|c|}
\hline \multirow{2}{*}{ Medida } & \multirow{2}{*}{ Subescalas } & \multicolumn{2}{|c|}{$\begin{array}{l}\text { Não Perfecionistas } \\
(N=20)\end{array}$} & \multicolumn{2}{|c|}{$\begin{array}{l}\text { Perfecionistas } \\
\quad(N=12)\end{array}$} & \multirow[b]{2}{*}{$\begin{array}{c}\text { rde } \\
\text { Cohen }\end{array}$} & \multirow[b]{2}{*}{$\boldsymbol{U}$} & \multirow[b]{2}{*}{$p$} \\
\hline & & M & $D P$ & $M$ & $D P$ & & & \\
\hline \multirow{4}{*}{ APS } & Padrão & 35.55 & 6.58 & 41.42 & 3.99 & -.44 & 56.50 & $.01^{*}$ \\
\hline & Ordem & 21.25 & 4.76 & 24.17 & 2.33 & -.28 & 80.00 & .12 \\
\hline & Discrepância & 38.25 & 11.46 & 55.75 & 10.59 & -.61 & 31.00 & $.00 * \star$ \\
\hline & Total & 95.05 & 10.59 & 121.33 & 10.74 & -.75 & 11.50 & $.00 * * *$ \\
\hline $\mathrm{PCl}$ & Total & 54.70 & 15.17 & 76.75 & 12.93 & -.63 & 29.00 & $.00 * * *$ \\
\hline
\end{tabular}


Nota. $M=$ Média; $D P=$ Desvio-Padrão; $r$ de Cohen; $U$ = Teste de Mann-Whitney para duas amostras independentes; Escala Quase Perfeita (APS) de Slaney et al. (1995); Inventário das Cognições Perfecionistas (PCI) de Flett et al. (1998)

${ }^{*} p<.05{ }^{* *} p<.01 .{ }^{* * *} p<.00$.

Em todas as dimensões analisadas existiram diferenças estatisticamente significativas entre os dois grupos, exceto na subescala Ordem $(U=80.00 ; p=.12)$.

No que diz respeito ao tamanho do efeito, através da fórmula de Cohen, pôde-se observar um efeito considerado médio na subescala Padrão $(r=-.44)$, um efeito pequeno na subescala Ordem ( $r=-.28)$, um efeito grande na subescala Discrepância $(r=-.61)$, um efeito consideravelmente elevado nas variáveis Total, tanto da medida APS $(r=-.75)$ como da medida PCI ( $r=-.63)$.

\section{TABELA 3}

Média, desvio-padrão e diferenças entre o grupo Não Perfecionistas ( $N=12)$ e o grupo Perfecionistas ( $N=$ 9) na Escala Multidimensional de Perfecionismo (HMPS)

\begin{tabular}{|c|c|c|c|c|c|c|c|c|}
\hline \multirow{2}{*}{ Medida } & \multirow{2}{*}{ Subescalas } & \multicolumn{2}{|c|}{$\begin{array}{l}\text { Não Perfecionistas } \\
(N=12)\end{array}$} & \multicolumn{2}{|c|}{$\begin{array}{l}\text { Perfecionistas } \\
\quad(N=9)\end{array}$} & \multirow[b]{2}{*}{$\begin{array}{l}\text { rde } \\
\text { Cohen }\end{array}$} & \multirow[b]{2}{*}{$\boldsymbol{U}$} & \multirow[b]{2}{*}{$p$} \\
\hline & & M & $D P$ & M & $D P$ & & & \\
\hline \multirow{4}{*}{ HMPS } & PAO & 61.33 & 15.58 & 96.33 & 7.53 & -.65 & 2.50 & $.00^{* * *}$ \\
\hline & PSP & 38.75 & 12.34 & 48.11 & 12.47 & -.29 & 31. & .10 \\
\hline & POO & 40.67 & 10.02 & 45.56 & 6.75 & -.21 & 37. & .23 \\
\hline & Total & 154.17 & 30.30 & 206.11 & 17.16 & -.58 & 8. & $.00 * \star$ \\
\hline
\end{tabular}

Nota. $M=$ Média; $D P=$ Desvio-Padrão; $r$ de Cohen; $U$ = Teste de Mann-Whitney para duas amostras independentes; Escala Multidimensional de Perfecionismo (HMPS) de Hewitt e Flett (1991). PAO = Perfecionismo Auto-Orientado; PSP = Perfecionismo Socialmente Prescrito; $P O O=$ Perfecionismo Orientado para os Outros

${ }^{*} p<.05 .{ }^{* *} p<.01 .{ }^{* * *} p<.00$.

Os dados demonstram que, embora os valores médios se apresentem superiores no grupo Perfecionistas em todas as dimensões, não se verificaram diferenças significativas entre os grupos em todas as dimensões desta medida de perfecionismo. Na subescala Perfecionismo Auto-Orientado (PAO) $(U=2.5 ; p=.00)$ e na variável total da escala $(U=8.0 ; p=.00)$ foram encontradas diferenças significativas entre os dois grupos em estudo.

No que respeita ao tamanho do efeito, obteve-se um efeito grande na subescala PAO $(r=-.65)$ e na variável Total $(r=-.58)$. Relativamente à subescala PSP $(r=-.29)$ e à subescala POO $(r=-.21)$ verificou-se a presença de um efeito pequeno.

\section{Relação entre medidas de perfecionismo}

De seguida, foi explorada a correlação entre as medidas de perfecionismo com o intuito de observar as relações entre as várias dimensões de perfecionismo. 
TABELA 4

Correlação entre as Dimensões da Escala Quase Perfeita (APS) e as Dimensões do Inventário das Cognições Perfecionistas $(P C l)(N=32)$

\begin{tabular}{ccc}
\hline APS & PCI \\
\hline Subescalas & Total \\
\hline Padrão & .33 \\
Ordem & $.37^{\star}$ \\
\hline Discrepância & $.55^{\star *}$ \\
\hline Total & $.69^{\star *}$ \\
\hline
\end{tabular}

Nota. $N=32$. Escala Quase Perfeita (APS) de Slaney et al. (1995); Inventário das Cognições Perfecionistas (PCI) de Flett et al. (1998). Assinalam-se as correlações moderadas e estatisticamente significativas ${ }^{*} p<.05 ;{ }^{* *} p<.01 ;{ }^{* *} p<.00$.

Ao analisar os coeficientes de correlação entre os dois instrumentos de medida do perfecionismo, foi evidente a presença de duas relações estatisticamente significativas. Deste modo, a subescala Discrepância (APS) apresentou uma relação positiva e moderada com o valor Total do Inventário das Cognições Perfecionistas (PCI) $\left(r_{s}=.55 ; p=.00\right)$. E, por fim, a relação entre o valor Total das duas também demonstrou ser significativa, positiva e forte $\left(r_{s}=.69 ; p=.00\right)$.

Foram igualmente realizadas as análises dos coeficientes de correlação de Pearson entre as restantes medidas em estudo. Contudo, por nenhum dos valores se revelar estatisticamente significativo, optou-se por não incluir a sua exposição.

\section{Tarefa de Revisão de Texto}

Para cada uma das variáveis (Erro Ortográfico, Gramatical e Formato de Texto) foram calculados cinco indicadores: Acerto (percentagem de deteção de erro quando existe erro); Falso Alarme (percentagem de deteção de erro quando não existe erro); Precisão (medida da capacidade de discriminação de situações com erro de situações sem erro); Viés de Resposta (tendência para ser conservador, isto é, tendência geral não referir que existe erro); e Eficiência da precisão (medida de eficiência baseada na precisão e no tempo).

Foi ainda adicionada uma quarta variável, denominada Item (medida global de desempenho), para a qual também foram calculados todos os indicadores acima referidos. A variável Tempo (duração da realização da tarefa) foi inserida no estudo, de forma a poder calcular a eficiência de cada participante.

Com base no artigo original, as medidas foram calculadas da seguinte forma: \%Acerto = $($ acertos +0.5$) /($ linhas do texto com erros +1$) ; \%$ Falso alarme $=($ falsos alarmes +0.5$) /($ linhas do texto sem erros + 1); Precisão = IDF.NORMAL (\%Acerto, 0, 1) - IDF.NORMAL (\%Falso alarme, 0, 1); Viés de resposta $=-0.5 \mathrm{x}$ (IDF.NORMAL (\%Acerto, 0, 1) + IDF.NORMAL (\%Falso alarme, 0, 1); Eficiência de precisão = (IDF.NORMAL (\%Acerto, 0, 1) - IDF.NORMAL (\%Falso alarme, 0, 1)/Tempo. O IDF.NORMAL (prob, mean, stddev) é uma função do software utilizado que retorna o valor da distribuição normal, com média (mean) e desvio padrão (stddev), para os quais a probabilidade cumulativa é prob.

As tarefas realizadas pelos participantes foram analisadas de modo a comparar o desempenho absoluto e o desempenho relativo (eficiência) entre os dois grupos, em relação à prova. 


\section{Análise intergrupal dos indicadores de desempenho}

Com recurso ao Teste de Mann-Whitney para amostras independentes, pretendeu-se comparar os valores médios da variável Tempo e dos indicadores das variáveis Erro Ortográfico (O), Erro Gramatical (G), Erro de Formato de Texto (T) e da variável Item (medida global de desempenho) para cada um dos grupos.

\section{TABELA 5}

Média, Desvio-Padrão e Diferenças entre o grupo Não Perfecionistas $(N=20)$ e o grupo Perfecionistas ( $N$ = 12) na variável Tempo e nos indicadores das variáveis Erro Ortográfico (O), Erro de Gramática (G), Erro de Formato de Texto (T) e Item

\begin{tabular}{|c|c|c|c|c|c|c|c|c|}
\hline \multirow[t]{2}{*}{ Variável } & \multirow[t]{2}{*}{ Indicadores } & \multicolumn{2}{|c|}{$\begin{array}{l}\text { Não Perfecionistas } \\
\qquad(N=20)\end{array}$} & \multicolumn{2}{|c|}{$\begin{array}{l}\text { Perfecionistas } \\
\quad(N=12)\end{array}$} & \multirow[b]{2}{*}{ rde Cohen } & \multirow[b]{2}{*}{$\boldsymbol{U}$} & \multirow[b]{2}{*}{$\boldsymbol{p}$} \\
\hline & & $M$ & $D P$ & $M$ & $D P$ & & & \\
\hline Tempo & & 1080.78 & 337.56 & 1138.75 & 341.60 & -.10 & 105.00 & .56 \\
\hline \multirow{5}{*}{ Erro 0} & Acerto & 0.51 & 0.23 & 0.60 & 0.12 & -.17 & 95.50 & .34 \\
\hline & FAlarme & 0.03 & 0.02 & 0.04 & 0.04 & -.11 & 103.50 & .52 \\
\hline & Precisão & 2.02 & 0.64 & 2.14 & 0.38 & -.13 & 101.00 & .46 \\
\hline & VResposta & 0.99 & 0.38 & 0.80 & 0.35 & -.24 & 85.00 & .17 \\
\hline & EPrecisão & 1.48 & 1.14 & 1.29 & 0.37 & -.06 & 111.00 & .73 \\
\hline \multirow{5}{*}{ Erro G } & Acerto & 0.46 & 0.19 & 0.38 & 0.12 & -.26 & 82.00 & .14 \\
\hline & FAlarme & 0.03 & 0.03 & 0.02 & 0.02 & -.20 & 91.50 & .26 \\
\hline & Precisão & 1.82 & 0.63 & 1.74 & 0.37 & -.06 & 111.00 & .73 \\
\hline & VResposta & 1.05 & 0.34 & 1.20 & 0.29 & -.23 & 86.00 & .19 \\
\hline & EPrecisão & 1.40 & 0.84 & 1.12 & 0.31 & -.06 & 112.00 & .76 \\
\hline \multirow{5}{*}{ Erro T } & Acerto & 0.82 & 0.21 & 0.79 & 0.20 & -.17 & 95.00 & .32 \\
\hline & FAlarme & 0.03 & 0.04 & 0.04 & 0.06 & .00 & 120.00 & 1.00 \\
\hline & Precisão & 3.21 & 1.03 & 2.98 & 0.87 & -.21 & 90.00 & .24 \\
\hline & VResposta & 0.48 & 0.36 & 0.48 & 0.48 & .00 & 120.00 & 1.00 \\
\hline & EPrecisão & 1.75 & 0.75 & 1.55 & 0.63 & -.16 & 97.00 & .37 \\
\hline \multirow{5}{*}{ Item } & Acerto & 0.68 & 0.14 & 0.67 & 0.11 & -.07 & 110.50 & .71 \\
\hline & FAlarme & 0.06 & 0.06 & 0.07 & 0.07 & -.09 & 107.00 & .61 \\
\hline & Precisão & 2.24 & 0.67 & 2.07 & 0.55 & -.21 & 89.50 & .24 \\
\hline & VResposta & 0.63 & 0.27 & 0.59 & 0.31 & -.05 & 112.50 & .77 \\
\hline & EPrecisão & 1.80 & 1.03 & 1.49 & 0.53 & -.12 & 103.00 & .51 \\
\hline
\end{tabular}

Nota. $M$ = Média; $D P$ = Desvio-Padrão; $r$ de Cohen; $U$ = Teste de Mann-Whitney para duas amostras independentes; Tempo = tempo (em segundos) que demorou a concluir a Tarefa de Revisão de Texto; Erro 0 = erro ortográfico presente na tarefa de revisão de texto; Erro G = erro gramática presente na tarefa de revisão de texto; Erro T = erro de formato de texto presente na tarefa de revisão de texto: Item = medida global de desempenho; Acerto = percentagem de deteção de erro quando existe erro; FAlarme = percentagem de deteção de erro quando não existe erro; Precisão = medida da capacidade de discriminação de situações com erro de situações sem erro; VResposta (Viés de Resposta) = tendência para ser conservador, i.e., referir que não existe erro; EPrecisão (Eficiência de precisão) = medida de eficiência baseada na precisão ${ }^{\star} p<.05 .{ }^{* *} p<.01 .{ }^{* *} p<.00$.

Ao analisar as diferenças entre o grupo Não Perfecionistas e o grupo Perfecionistas, estas não demonstraram ser estatisticamente significativas em nenhuma das variáveis em estudo.

Considerando o tamanho do efeito da variável Tempo, pôde-se constatar a presença de um efeito consideravelmente pequeno $(r=-.10)$. No que respeita ao tamanho do efeito da variável 
Erro O, também se obteve um efeito pequeno em todos os seus indicadores, como por exemplo no indicador Falso Alarme ( $r=-.11$ ) e no indicador Eficiência da Precisão ( $r=-.06)$.

Relativamente ao tamanho do efeito da variável Erro G, obteve-se um efeito pequeno em todos os seus indicadores, como por exemplo no indicador Precisão $(r=-.06)$ ou no indicador Viés de Resposta $(r=-.23)$. Do mesmo modo, também a variável Erro T demonstrou ter um efeito pequeno em todos os indicadores, como por exemplo no indicador Acerto $(r=-.17)$ e no indicador Precisão $(r=-.21)$.

Por último, verificou-se um efeito pequeno em todos os indicadores da variável Item, como por exemplo nos indicadores Acerto $(r=-.07)$ e Viés de Resposta $(r=-.05)$.

\section{Relação entre os indicadores de desempenho e as medidas de perfecionismo}

De seguida, encontraram-se descritos os coeficientes de correlação de Pearson entre a variável Tempo, os cinco indicadores das variáveis Erro Ortográfico (O), Erro Gramatical (G), Erro de Formato de Texto (T), variável Item (medida global de desempenho) e as medidas de perfecionismo em análise.

\section{Variável Tempo}

\section{TABELA 6}

Correlação entre a variável Tempo e a Escala Quase Perfeita (APS), o Inventário das Cognições Perfecionistas (PCI) e a Escala Multidimensional do Perfecionismo (HMPS)

\begin{tabular}{cccccccccc}
\hline & \multicolumn{3}{c}{ APS } & \multicolumn{3}{c}{ PCI } & \multicolumn{3}{c}{ HMPS } \\
\hline & P & $\mathbf{0}$ & $\mathbf{D}$ & Total & Total & PAO & PSP & PO0 & Total \\
\hline Tempo & .26 & .04 & .08 & .17 & .13 & $.48^{\star}$ & .18 & .31 & $.45^{\star}$ \\
\hline
\end{tabular}

Nota. $N=32$. Tempo = tempo (em segundos) que demorou a concluir a Tarefa de Revisão de Texto. Escala Quase Perfeita (APS) de Slaney et al. (1995); P = Padrão; O = Ordem; D = Discrepância; Total APS = Valor total de perfeccionismo avaliado pela APS. Inventário das Cognições Perfecionistas (PCI) de Flett et al. (1998); Total PCI = Valor total de perfecionismo avaliado pelo PCI. Escala Multidimensional de Perfecionismo (HMPS) de Hewitt e Flett (1991); PAO = Perfecionismo Auto-Orientado; PSP = Perfecionismo Socialmente Prescrito; P00 = Perfecionismo Orientado para os Outros; Total HMPS = Valor total de perfecionismo avaliado pela HMPS. Assinalam-se as correlações moderadas e estatisticamente significativas ${ }^{\star} p<.05 ;{ }^{* *} p<.01 ;{ }^{* *} p<.00$.

Ao analisar os coeficientes de correlação entre a variável Tempo e as várias subescalas das medidas de perfecionismo, é possivel compreender a existência de uma relação positiva, moderada e estatisticamente significativa entre o Tempo e a subescala PAO $\left(r_{s}=.48 ; p=.03\right)$ e com o valor Total da escala $\left(r_{s}=.45 ; p=.04\right)$.

No entanto, nenhuma das outras relações entre a variável Tempo e as restantes subescalas das medidas de perfecionismo se mostraram significativas. 


\section{Variável Erro Ortográfico (O)}

\section{TABELA 7}

Correlação entre a variável Erro Ortográfico (O) e a Escala Quase Perfeita (APS), o Inventário das Cognições Perfecionistas (PCI) e a Escala Multidimensional do Perfecionismo (HMPS)

\begin{tabular}{lccccccccc}
\hline & \multicolumn{3}{c}{ APS } & \multicolumn{3}{c}{ PCI } & \multicolumn{3}{c}{ HMPS } \\
\hline Erro 0 & P & $\mathbf{0}$ & $\mathbf{D}$ & Total & Total & PAO & PSP & PO0 & Total \\
\hline Acerto & .320 & .28 & .16 & .330 & .08 & .16 & .31 & -.02 & .20 \\
FAlarme & .20 & .26 & .22 & .330 & $.44^{\star}$ & $.44^{\star}$ & .33 & .33 & $.48^{\star}$ \\
Precisão & .16 & .09 & .07 & .14 & -.24 & -.18 & .04 & -.25 & -.17 \\
VResposta & -.340 & -.340 & -.17 & $-.35^{\star}$ & -.27 & -.37 & -.410 & -.17 & -.420 \\
EPrecisão & -.07 & .01 & -.06 & -.07 & $-.38^{*}$ & $-.45^{\star}$ & -.07 & -.36 & -.410 \\
\hline
\end{tabular}

Nota. $N=32$. Erro 0 = erro ortográfico presente na tarefa de revisão de texto. Acerto = percentagem de deteção de erro quando existe erro. FAlarme (Falso Alarme) = percentagem de deteção de erro quando não existe erro. Precisão = medida da capacidade de discriminação de situações com erro de situações sem erro. VResposta (Viés de Resposta) = tendência para ser conservador, i.e., referir que não existe erro. EPrecisão (Eficiência de precisão) = medida de eficiência baseada na precisão. Escala Quase Perfeita (APS) de Slaney et al. (1995); P = Padrão; 0 = Ordem; D = Discrepância; Total APS = Valor total de perfeccionismo avaliado pela APS. Inventário das Cognições Perfecionistas (PCI) de Flett et al. (1998); Total PCI = Valor total de perfecionismo avaliado pelo PCI. Escala Multidimensional de Perfecionismo (HMPS) de Hewitt e Flett (1991) PAO = Perfecionismo Auto-Orientado; PSP = Perfecionismo Socialmente Prescrito; POO = Perfecionismo Orientado para os Outros; Total HMPS = Valor total de perfecionismo avaliado pela HMPS. Assinalam-se as correlações moderadas e estatisticamente significativas ${ }^{*} p<.05 ;{ }^{* *} p<.01 ;{ }^{* * *} p<.00$.

${ }^{\circ} p<0.10$.

Com base nos dados obtidos, foram observados coeficientes de correlação estatisticamente significativos entre o indicador Viés de Resposta e a variável Total do APS $\left(r_{s}=-.35 ; p=.05\right)$ que demonstrou ser uma relação negativa e fraca.

Também se verificou a existência de relações significativas entre o indicador Falso Alarme e a variável Total do PCI $\left(r_{s}=.44 ; p=.01\right)$, que demonstrou ser positiva e moderada, e entre o indicador Eficiência da Precisão e a variável Total do PCI $\left(r_{s}=-.38 ; p=.04\right)$ que, pelo contrário, mostrou ser negativa e fraca.

A relação entre os indicadores da variável Erro O e o HMPS mostrou ser positiva, moderada e significativa entre o indicador Falso Alarme e a subescala PAO $\left(r_{s}=.44 ; p=.05\right)$ e a variável Total $\left(r_{s}=.48 ; p=.03\right)$. O indicador Eficiência da Precisão mostrou ter uma relação negativa, moderada e significativa com a subescala PAO $\left(r_{s}=-.45 ; p=.04\right)$.

\section{Variável Erro Gramatical (G)}

Posteriormente, foram analisadas as relações entre os indicadores da variável Erro Gramatical $(G)$ e as medidas de perfecionismo.

De acordo com os coeficientes de correlação alcançados, não foram observáveis relações estatisticamente significativas entre os indicadores da variável Erro G e o APS assim como entre os indicadores da variável Erro G e o PCI.

Por outro lado, os coeficientes de correlação entre os indicadores da variável Erro G e o HMPS demostraram a presença de algumas relações significativas. $\mathrm{O}$ indicador Eficiência da Precisão apresentou uma relação negativa, moderada e significativa com a subescala PAO $\left(r_{s}=-.45 ; p=.04\right)$ e com a variável Total $\left(r_{s}=-.45 ; p=.04\right)$. 


\section{Variável Erro de Formato de Texto (T)}

De seguida, as relações entre os indicadores da variável Erro de Formato de Texto (T) e as medidas de perfecionismo foram analisadas.

Ao observar os coeficientes de correlação referidos, foi possível concluir que não existiram relações estatisticamente significativas entre os indicadores da variável Erro $\mathrm{T}$ e qualquer medida do perfecionismo.

\section{Variável Item}

Ao analisar a relação entre os indicadores da variável Item e as medidas de perfecionismo apenas se encontrou uma correlação estatisticamente significativa, entre o indicador Viés de Resposta e a subescala $\mathrm{P}\left(r_{s}=-.38 ; p=.03\right)$, que demonstrou ser fraca e negativa. Embora marginalmente significativa, o indicador Eficiência da Precisão apresentou uma relação com a subescala PAO $\left(r_{s}=-.41 ; p=.07\right)$, sendo esta negativa e moderada.

\section{Discussão}

A análise das caraterísticas sociodemográficas do grupo Não Perfecionistas e do grupo Perfecionistas não revelou diferenças estatisticamente significativas, demonstrando que as amostras são homogéneas. Eventuais diferenças entre os grupos encontrar-se-ão relacionadas com outros fatores.

No primeiro momento da investigação pretendeu-se discriminar os sujeitos com altos e baixos níveis de perfecionismo e procedeu-se à divisão da amostra através da medida de perfecionismo utilizada (SAPS).

Com o intuito de melhor compreender e caracterizar a componente cognitiva do conceito, procedeu-se à realização e análise do segundo momento.

Ao observar os Níveis de Perfecionismo (APS), constatou-se que os sujeitos Perfecionistas apresentaram níveis superiores - como se esperava. Este grupo exibiu Padrões Pessoais de desempenho superiores e maior perceção da Discrepância entre os seus padrões pessoais e a sua capacidade de os alcançar relativamente ao grupo dos sujeitos Não Perfecionistas. Relativamente ao Perfecionismo Geral (HMPS), o grupo Perfecionistas também apresentou valores superiores. Os sujeitos Perfecionistas demonstraram uma tendência para estabelecer mais normas e padrões de desempenho elevados e rigorosos em relação a si mesmos, como seria de esperar.

Ao investigar a frequência das Cognições Perfecionistas (PCI), observou-se que os valores foram superiores nos sujeitos Perfecionistas. Este facto mostra que este foi um instrumento discriminatório entre os grupos, o que corrobora o estudo de Ishida (2005) onde esta medida de perfecionismo permitiu dividir a amostra em dois grupos - Perfecionistas e Não Perfecionistas.

Os dados anteriores denotam que os sujeitos Perfecionistas que aceitaram dar continuidade ao estudo apresentaram características de perfecionismo diferentes dos sujeitos Não Perfecionistas. Deste modo, pode-se caraterizar os sujeitos Perfecionistas por apresentarem Niveis de Perfecionismo elevados (APS); Padrões Pessoais de desempenho mais elevados; maior perceção da Discrepância; maior frequência de Cognições Perfecionistas (PCI); e por serem mais exigentes consigo próprios. Respondendo a um dos objetivos delineados para a presente investigação, 
houve diferenças nas várias dimensões de perfecionismo em sujeitos com altos e baixos níveis de perfecionismo.

Seguidamente, ao analisar as relações entre as várias dimensões de perfecionismo foi possível verificar (apesar de muito circunscritas) algumas relações significativas entre as dimensões. Observou-se que os sujeitos Perfecionistas que apresentaram uma maior preferência pela organização, Ordem e limpeza e uma perceção de si mesmos como incapazes de alcançar os seus padrões de desempenho, tenderam a apresentar mais Cognições Perfecionistas (PCI). Este facto mostra que a componente comportamental se relaciona com a componente cognitiva, uma vez que elevados Níveis de Perfecionismo (APS) correspondem a maior frequência de Cognições Perfecionistas (PCI).

O objetivo principal da tarefa de revisão de texto consistiu em avaliar se existiam diferenças no desempenho na realização da prova em sujeitos com altos e baixos níveis de perfecionismo. Embora no artigo original desenvolvido por Stoeber e Eysenck (2008) as modalidades de erro não sejam discriminadas (i.e., referem-se aos erros no global), no presente trabalho os diferentes tipos de erro encontram-se devidamente diferenciados.

Apesar da maioria das relações não serem significativas na análise intergrupal, percecionou-se que os sujeitos Perfecionistas tenderem a demorar mais tempo a concluir a tarefa. No estudo de Ishida (2005) os sujeitos Perfecionistas investiram mais tempo nas informações irrelevantes, apresentando uma eficiência reduzida comparativamente aos sujeitos Não Perfecionistas. Assim, os dados alcançados no presente estudo vão de encontro ao esperado.

No que diz respeito aos indicadores das variáveis Erro Ortográfico, Erro Gramatical, Erro Formato de Texto e da variável Item não se observaram diferenças entre os dois grupos em estudo, sugerindo a ambiguidade de deteção de erros. O facto de não haver qualquer tipo de discriminação de Erro pode estar relacionado com o tamanho da amostra, que não permitiu uma expressão significativa dos resultados; e com algumas caraterísticas do texto selecionado, nomeadamente em palavras de dupla grafia.

Os sujeitos que mostraram ser mais perfecionistas no global (HMPS) tenderam a demorar mais tempo a concluir a tarefa, especialmente os que tenderam a ser mais exigentes consigo mesmos. No estudo original, os participantes que demoraram mais tempo tiveram um maior investimento para encontrar os erros, apresentando maior precisão mas menor eficiência (Stoeber $\delta$ Eysenck, 2008).

Ao investigar a variável Erro Ortográfico, foi possível verificar que os sujeitos com mais Cognições Perfecionistas (PCI) e mais exigentes consigo mesmos tenderam a detetar/assinalar mais erros quando na verdade não se tratava de um erro (Falsos Alarmes). De acordo com Shafran et al. (2002), os Perfecionistas sentem uma pressão constante para alcançar a perfeição o que potencia o insucesso, por estabelecerem objetivos irrealistas, levando à diminuição do desempenho e da produtividade.

Também foi possível verificar que quanto maiores os Níveis de Perfecionismo (APS) menor o Viés de Resposta, i.e., menor a tendência para ser conservador. Este dado parece mostrar que quanto mais elevados foram os níveis de perfecionismo, maior foi a tendência de referir que existia erro. Assim, esta relação mostrou que os sujeitos Perfecionistas referiram mais Erros Ortográficos no texto do que os sujeitos Não Perfecionistas. Um dos motivos pelos quais isto acontece pode ser por este tipo de erros serem aqueles que os participantes estavam mais seguros, uma vez que todos eram nativos de língua portuguesa. Outro motivo pode ser o facto de os Erros 
Ortográficos serem os menos ambíguos comparativamente aos de Gramática ou mesmo de Formatação, que implicavam ler as regras descritas nas instruções.

Outro objetivo da presente investigação consistia em explorar a relação entre as Cognições Perfecionistas (PCI) e a eficiência na resolução da tarefa. Através dos dados alcançados, constatou-se que os sujeitos que apresentaram mais Cognições Perfecionistas (PCI) foram menos eficientes quanto ao Erro Ortográfico. Também os sujeitos Perfecionistas com tendência para ser exigentes consigo mesmos demonstraram ser menos eficientes.

Analisar a relação entre os Niveis de Perfecionismo (APS) e a eficiência na resolução da tarefa também foi um objetivo delineado. No presente estudo não foi possível encontrar qualquer relação significativa. Ainda assim sublinhamos que, apesar de não ser uma relação significativa, a eficiência se relacionou negativamente com os Padrões Pessoais de desempenho - i.e., os sujeitos com Padrões Pessoais elevados tenderam a ser menos eficientes, o que corrobora os resultados do estudo de Stoeber e Eysenck (2008).

Os sujeitos Perfecionistas que apresentavam Padrões Pessoais de desempenho elevados tenderam a detetar (Acertar) os Erros de Ortografia e sujeitos Perfecionistas no global (HMPS), apresentaram um elevado número de Falsos Alarmes. Não é possível contrastar estes resultados com os estudos anteriores na área porque as modalidades de erros foram sempre agrupadas.

Sujeitos Perfecionistas com Padrões Pessoais de desempenho elevados, com tendência para a organização e Ordem e com expetativas sociais face a si mesmos tenderam a apresentar um menor viés de resposta (referiram que existia Erro Ortográfico). Deste modo, depreende-se que os sujeitos perfecionistas tenderam a ser menos conservadores nas suas respostas, face ao Erro Ortográfico.

Seguidamente, ao analisar a medida global de desempenho (Item), constatou-se que os sujeitos com Padrões Pessoais de desempenho elevados tenderam a ser menos conservadores (i.e., referiram mais vezes que existia erro). Também foi possivel observar que, no presente estudo, os sujeitos com perfecionismo direcionado para o próprio tenderam a ser menos eficientes na resolução da Tarefa.

Assim, tal como seria de esperar, pode-se concluir que quanto maiores os Níveis de Perfecionismo menor o desempenho relativo (ou eficiência) dos participantes. Os sujeitos Perfecionistas tenderam a ser menos eficientes no seu desempenho, corroborando assim os resultados do estudo de Stoeber e Eysenck (2008). Deste modo, tanto os resultados do estudo original como do presente estudo fornecem apoio empírico para o facto de que o perfecionismo se encontra inversamente relacionado com a eficiência (Ishida, 2005).

\section{Considerações finais}

O presente estudo apresentou como principal finalidade analisar a influência das Cognições Perfecionistas no desempenho de uma tarefa de revisão de texto. Neste sentido, procurou-se averiguar se a qualidade do desempenho dos sujeitos dependia dos seus Níveis de Perfecionismo.

Ao analisar as diferenças intergrupais, percecionou-se que os sujeitos Perfecionistas demoraram mais tempo a realizar a prova - especialmente os que mostravam ser exigentes em relação a si próprios - e investiram mais a encontrar erros. Embora apresentem um maior número de Acertos, também apresentam um maior número de Falsos Alarmes. 
Os resultados alcançados neste estudo apresentam implicações importantes para as investigações sobre o perfecionismo e o desempenho. Como esperado, o perfecionismo está negativamente relacionado com a eficiência. Sem considerar a eficiência e as respostas corretas versus incorretas, pode-se concluir que não houve diferenças estatisticamente significativas no desempenho na prova em função dos Níveis de Perfecionismo.

A presente investigação apresenta algumas limitações. Primeiro, aponta-se o facto de a amostra ter sido reduzida. Segundo, o texto selecionado para a tarefa de revisão de texto pode ser considerado como uma limitação por ser ambíguo, suscitando dúvidas e dificultando a deteção correta dos erros. E terceiro, existem poucos estudos que tenham investigado o perfecionismo e a eficiência utilizando o tempo para determinar o esforço, o que dificulta a compreensão e a interpretação dos resultados alcançados.

Estudos futuros podem incluir na investigação outros indicadores de esforço, como por exemplo o esforço subjetivo, o grau de atenção e os indicadores fisiológicos (Eysenck et al., 2007) de modo a averiguar se os presentes resultados são generalizáveis. Outras sugestões de estudos futuros podem ser a realização da investigação em apenas um momento, de forma a não se perderem participantes, e a seleção de um texto de fácil leitura, mais reduzido e aprimorado.

\section{Referências}

Adler, A. (1956). The neurotic disposition. In Ansbacher, H. L., \& Ansbacher, R. R. (Eds.), The individual psychology of Alfred Adler (pp. 239-262). New York

Antony, M. M., Purdon, C. L., Huta, V., \& Swinson, R. P. (1998). Dimensions of perfectionism across the anxiety disorders. Behaviour Research and Therapy, 36(12), 1143-1154. https://doi.org/10.1016/S00057967(98)00083-7

Bong, M., Hwang, A., Noh, A., \& Kim, S. (2014). Perfectionism and Motivation of Adolescents in Academic Contexts. Journal of Educational Psychology, 106(3), 711-729. https://doi.org/10.1037/a0035836

Burns, D. D. (1980). The Perfectionist's Script for Self-defeat. Psychology Today, 14(6), 34-52

Carmo, C., Cotão, P., Brás, M., \& Faísca, L. (2018). Propriedades psicométricas do Inventário de Cognições Perfecionistas : um estudo preliminar numa amostra de adultos portugueses, 17(3). https://doi.org/10.1007/ BF01176069

Dunn, J. G. H., Gotwals, J. K., Dunn, J. C., \& Syrotuik, D. G. (2006). Examining the relationship between perfectionism and trait anger in competitive sport. International Journal of Sport and Exercise Psychology, 4(1), 7-24. https://doi.org/10.1080/1612197X.2006.9671781

Egan, S. J., Wade, T. D., \& Shafran, R. (2011). Perfectionism as a transdiagnostic process: A clinical review. Clinical Psychology Review, 31(2), 203-212. https://doi.org/10.1016/j.cpr.2010.04.009

Egan, S. J., Wade, T. D., \& Shafran, R. (2012). The transdiagnostic process of perfectionism. Revista de Psicopatologia y Psicologia Clinica, 17(3), 279-294. https://doi.org/10.5944/rppc.vol.17.num.3.2012.11844

Enns, M. W., \& Cox, B. J. (2002). The nature and assessment of perfectionism: A critical analysis. In Flett, G. L., \& Hewitt, P. L. (Eds.), Perfectionism: Theory, research, and treatment (pp. 33-62). American Psychological Association. https://doi.org/10.1037/10458-002

Eysenck, M. W., \& Calvo, M. G. (1992). Anxiety and Performance: The Processing Efficiency Theory. Journal Cognition and Emotion, 6(6), 409-434. https://doi.org/10.1080/02699939208409696 
Flett, G. L., Hewitt, P. L., Blankstein, K. R., \& Gray, L. (1998). Psychological distress and the frequency of perfectionistic thinking. Journal of Personality and Social Psychology, 75(5), 1363-1381. https://doi. org/10.1037/0022-3514.75.5.1363

Flett, G. L., Nepon, T., \& Hewitt, P. L. (2015). Perfectionism, Worry, and Rumination in Health and Mental Health: A Review and a Conceptual Framework for a Cognitive Theory of Perfectionism. In Sirois, F., \& Molnar, D. (Eds.), Perfectionism, Health, and Well-Being (p. 121-155). Springer International Publishing AG. https://doi.org/10.1007/978-3-319-18582-8_6

Flett, Hewitt, P. L., Shapiro, B., \& Rayman, J. (2002). Perfectionism, beliefs, and adjustment in dating relationships. Current Psychology: A Journal for Diverse Perspectives on Diverse Psychological Issues, 20(4), 289-311. https://doi.org/10.1007/s12144-001-1013-4

Frost, R. O., Marten, P., Lahart, C., \& Rosenblate, R. (1990). The Dimensions of Perfectionism. Cognitive Therapy and Research, 14(5), 449-468. https://doi.org/10.1007/BF01172967

Gaudreau, P., \& Thompson, A. (2010). Testing a 2x2 model of dispositional perfectionism. Personality and Individual Differences, 48(5), 532-537. https://doi.org/10.1016/j.paid.2009.11.031

Hamachek, D. E. (1978). Psychodynamics of normal and neurotic perfectionism. Psychology: A Journal of Human Behavior, 15(1), 27-33

Hewitt, P. L., \& Flett, G. L. (1991). Perfectionism in the self and social contexts: conceptualization, assessment, and association with psychopathology. Journal of Personality and Social Psychology, 60(3), 456470. https://doi.org/10.1037/0022-3514.60.3.456

Hollender, M. H. (1965). Perfectionism. Comprehensive Psychiatry, 6(2), 94-103. https://doi.org/10.1016/ S0010-440X(65)80016-5

Hollender, M. H. (1978). Perfectinism, a neglected personality trait. Journal of Clinical Psychiatry, 39, 384

Horney, K. (1945). Our Inner Conflicts: A Constructive Theory of Neurosis. New York

Ishida, H. (2005). College students' perfectionism and task-strategy inefficiency: Why their efforts go unrewarded? Japanese Journal of Social Psychology, 20(3), 208-215

Kline, P. (1999). The handbook of psychological testing (2nd ed.). London: Routledge

Macedo, A., Soares, M. J., Maia, B., Pereira, A. T., Marques, M., Bos, S., Gomes, A. A., \& Azevedo, M. H. (2007). Perfecionismo e Psicopatologia. Psiquiatria Clínica, 28(2 e 3), 5-14

O'Connor, R. C., Rasmussen, S., \& Hawton, K. (2010). Predicting depression, anxiety and self-harm in adolescents: The role of perfectionism and acute life stress. Behaviour Research and Therapy, 48(1), 52-59. https://doi.org/10.1016/j.brat.2009.09.008

Ram, A. (2005). The Relationship of Positive and Negative Perfectionism to Academic Achievement, Achievement Motivation, and Well-Being in Tertiary Students [Master's thesis, University of Canterbury]. University of Canterbury Research Repository. http://hdl.handle.net/10092/1300

Rice, Richardson, C., \& Tueller, S. (2014). The Short Form of the Revised Almost Perfect Scale. Journal of Personality Assessment, 96(3), 368-379. https://doi.org/10.1080/00223891.2013.838172

Shafran, R., Cooper, Z., \& Fairburn, C. (2002). Clinical perfectionism: a cognitive-behavioural analysis. Behaviour Research and Therapy, 40(7), 773-791. https://doi.org/10.1016/s0005-7967(01)00059-6. PMID: 12074372

Shafran, R., \& Mansell, W. (2001). Perfectionism and Psychopathology: A Review of Research and Treatment. Clinical Psychology Review, 21(6), 879-906. https://doi.org/10.1016/S0272-7358(00)00072-6 
Sherry, S. B., Hewitt, P. L., Flett, G. L., \& Harvey, M. (2003). Perfectionism Dimensions, Perfectionistic Attitudes, Dependent Attitudes, and Depression in Psychiatric Patients and University Students. Journal of Counseling Psychology, 50(3), 373-386. https://doi.org/10.1037/0022-0167.50.3.373

Slaney, Ashby, J. S., \& Trippi, J. (1995). Perfectionism: Its Measurement and Career Relevance. Journal of Career Assessment, 3(3), 279-297. https://doi.org/10.1177/106907279500300403

Slaney, R. B., Chadha, N., Mobley, M., \& Kennedy, S. (2000). Perfectionism in Asian Indians: Exploring the Meaning of the Construct in India. Counseling Psychologist, 28, 10-31

Slaney, R. B., Rice, K. G., Mobley, M., Trippi, J., \& Ashby, J. S. (2001). The Revised Almost Perfect Scale. Measurement and Evaluation in Counseling and Development, 34(3), 130-145. https://doi.org/10.1080/0 7481756.2002.12069030

Soares, M. J., Gomes, A., Macedo, A., \& Azevedo, M. (2003). Escala Multidimensional de Perfeccionismo: Adaptação À População Portuguesa. Revista Portuguesa De Psicossomática, 5(1), 46-55

Sousa, V. D., Driessnack, M., \& Mendes, I. A. C. (2007). Revisão dos Desenhos de Pesquisa Relevantes para Enfermagem. Parte 1: Desenhos de Pesquisa Quantitativa. Revista Latino-Americana de Enfermagem, 15(3), 684-688. https://doi.org/10.1590/S0104-11692007000400025

Stoeber, J. (2011). Perfectionism, efficiency, and response bias in proof-reading performance: Extension and replication. Personality and Individual Differences, 50, 426-429. https://doi.org/10.1016/j. paid.2010.10.021

Stoeber, J. (2018). The psychology of perfectionism: Critical issues, open questions, and future directions. In Stoeber, J. (Eds.), The Psychology of Perfectionism: Theory, Research, Applications (pp. 333-352). London: Routledge

Stoeber, J., \& Eysenck, M. W. (2008). Perfectionism and efficiency: Accuracy, response bias, and invested time in proof-reading performance. Journal of Research in Personality, 42(6), 1673-1678. https://doi. org/10.1016/j.jrp.2008.08.001

Stoeber, J., \& Otto, K. (2006). Positive conceptions of perfectionism: Approaches, evidence, challenges. Personality and Social Psychology Review, 10(4), 295-319. https://doi.org/10.1207/s15327957pspr1004

Wu, K. D., \& Cortesi, G. T. (2009). Relations between perfectionism and obsessive-compulsive symptoms: Examination of specificity among the dimensions. Journal of Anxiety Disorders, 23(3), 393-400. https://doi.org/10.1016/j.janxdis.2008.11.006 